\title{
Effect of Diallyl Sulphide, Diallyl Disulphide, and Allyl Methyl Sulphide on the Inhibition of Lung Metastasis of B16F-10 Melanoma Cells in Mice
}

\author{
Girija KutTAN* and Ramadasan KutTAN \\ Amala Cancer Research Centre, Amala Nagar, \\ Thrissur 680553, Kerala, India
}

(Received June 6, 1999)

\begin{abstract}
Summary Effect of naturally occurring sulphur-containing compounds such as diallyl sulphide (DAS), diallyl disulphide (DADS), and allyl methyl sulphide (AMS) on the inhibition of lung metastasis of B16F-10 melanoma cells was studied in C57BL/6 mice. Simultaneous administration of the compounds after tumor induction produced a significant reduction in tumor nodule formation (DAS 55\%, DADS 90\%, and AMS 54\%). The effect was lower when the compounds were administered after tumor development, whereas prophylactic administration of the compounds did not have any effect on lung tumor nodule formation. Increased lung collagen hydroxyproline, serum sialic acid, and gamma glutamyl transpeptidase activity in the metastasized lungs of control animals was significantly reduced in the animals treated with the sulphurcontaining compounds. Pathology of the lung tissue also correlated with the above findings. Our results are indicative of the antimetastatic activity of these sulphur-containing compounds.
\end{abstract}

Key Words: diallyl sulphide, diallyl disulphide, allyl methyl sulphide, metastasis, melanoma

The process of metastasis of cancer cells begins early in the growth of the primary tumor. This involves a cascade of sequential inter-related steps [1-3]. Metastasis begins by the initial separation of the tumor cell from the primary tumor, entry into circulation, attachment to the vascular wall, and extravasation to a new site. As the organs are highly protected by the interstitium, this process involes degradation of the basement membrane by specific proteolytic enzymes

\footnotetext{
* To whom correspondence should be addressed.
} 
liberated from the metastatic cells. Once the tumor cells reach the secondary site, they begin mitosis and develop into new colonies.

Metastasis of cancer cells is a threat to the available cancer therapy and is a major reason for treatment failure. Medicines available presently are cytoreductive drugs, which are non-specific. Earlier we showed that metastasis could be inhibited by polyphenolic compounds, such as catechin and curcumin [4] which were found to produce artificial cross links with collagen [5] and thereby to inhibit the action of proteolytic enzymes. Metalloproteases are present in an inactive form in which the metal containing active site is bound by a prodomain region having a cysteine residue at the end. Activation involves removal of the prodomain site by proteolytic enzymes. The active form of the enzyme is inactivated by low concentrations of cysteine, $n$-acetylcysteine, etc. In fact, $n$-acetylcysteine has been shown to inhibit metastasis [6].

In the present study the effect of naturally occurring sulphur compounds, namely, diallyl sulphide (DAS) $\left[\left(\mathrm{CH}_{2}=\mathrm{CH}-\mathrm{CH}_{2}\right)_{2} \mathrm{~S}\right]$, diallyl disulphide (DADS) $\left[\mathrm{CH}_{2}=\mathrm{CH}-\mathrm{CH}_{2}-\mathrm{S}-\mathrm{S}-\mathrm{CH}_{2}-\mathrm{CH}=\mathrm{CH}_{2}\right]$, allyl methyl sulphide (AMS) $\left[\mathrm{CH}_{2}=\mathrm{CH}-\right.$ $\mathrm{CH}_{2}-\mathrm{S}-\mathrm{CH}_{3}$ ] in the inhibition of lung metastasis by B16F-10 melanoma cells in $\mathrm{C} 57 \mathrm{BL} / 6$ mice was studied.

\section{MATERIALS AND METHODS}

C57BL/6 mice were purchased from the National Institute of Nutrition (Hyderabad, India). The animals were maintained in ventilated cages, and fed mouse chow (Lipton, India) and water ad libitum.

All the animal experiments were done as per the guidelines laid down by the Committee for the Purpose of Control and Supervision of Experiments on Animal (Govt. of India).

Cell lines. B16F-10 melanoma cells were obtained from the National Centre for Cell Science, Pune, India. The cells were maintained in Dulbecco's minimum essential medium supplemented with $10 \%$ fetal calf's serum and antibiotics.

DAS was purchased from Sigma (St. Louis, MO) and DADS and AMS were from Aldrich Chemicals (Milwaukee, WI). Hydroxyproline was a gift from Dr. K. Balasubramanium (Wellcome Research Unit, Vellore, India) and sialic acid was donated by Dr. A.S. Balasubramanium (Department of Neurochemistry, Christian Medical College and Hospital, Vellore, India). All other reagents were of analytical reagent quality.

Drug administration. The compounds were diluted in paraffin oil to the desired concentration $(20 \mathrm{mg} / \mathrm{kg}$ body weight/dose/animal) and were administered intraperitoneally. Drugs were administered either a) simultaneously from the same day of tumor inoculation and were continued for 10 consecutive days, b) after 10 days of tumor development ( 10 daily doses) or c) prophylactically by 10 daily doses of drug prior to tumor inoculation.

Effect of various sulphur-containing compounds on lung tumor nodule 
formation. Metastatic B16F-10 melanoma cells $\left(10^{6}\right)$ were injected into 6-8-weekold C57BL/6 mice (20-25 g) through a lateral tail vein. They were separated into 3 groups. The first group was treated with the drug simultaneously with injection of tumor cells, the second group was treated after tumor development, and the third group was treated prophylactically. These groups were further sub-divided into 4 sub-groups ( 8 animals/sub-group). The first sub-group was used as a control treated with 10 daily doses of paraffin $(0.1 \mathrm{ml})$. The other 3 sub-groups were treated either with DAS, DADS, or AMS (20 mg/ $\mathrm{kg}$ body weight/dose/animal). The animals were sacrificed on the 21 st day after tumor induction, the lungs were excised and the number of lung tumor colonies was counted. Lung tissue was used to estimate lung collagen hydroxyproline content and for histopathological analysis. Blood was collected by heart puncture, and the serum was separated and used to estimate serum sialic acid and gamma glutamyl transpeptidase (GGT) levels as described below.

Effect of sulphur-containing compounds on the survival rate of metastatic tumor-bearing animals. Metastatic tumor B16F-10 melanoma cells were injected into $\mathrm{C} 57 \mathrm{BL} / 6$ mice through a lateral tail vein. The animals were divided into 3 groups, and each group was treated by the three different modalities as given above. Each group was further sub-divided into 4 sub-groups (6 animals/subgroup). The first sub-group received 10 daily doses of paraffin oil and was used as a control. The other sub-groups were treated with either DAS, DADS, or AMS. The percentage increase in life span was calculated from the formula \%ILS $=(T-$ $C) / C \times 100$, where $C$ represents the average life span of control animals and $T$ represents the average life span of treated animals. Death of the animals due to tumor burden was recorded every day.

Effect of the sulphur-containing compounds on lung collagen hydroxyproline, serum sialic acid, and serum GGT levels. Lungs were homogenized and the protein was precipitated with TCA and hydrolyzed with $6 \mathrm{~N} \mathrm{HCl}$. The hydrolysate was evaporated to dryness, the residue dissolved in water, and neutralized and the hydroxyproline estimated by the chloramine-T method [7].

Protein-bound serum sialic acid was estimated by the thiobarbituric acid assay [8]. Serum was hydrolyzed with $0.2 \mathrm{~N}$ sulphuric acid. The hydrolysate was oxidized with periodic acid and incubated at $37^{\circ} \mathrm{C}$ for $30 \mathrm{~min}$. After termination of oxidation with sodium arsenite, $6 \%$ thiobarbituric acid was added; and the reaction mixture was then heated at $60^{\circ} \mathrm{C}$ and an equal volume of dimethyl sulphoxide $(0.4 \mu 1)$ was added. Absorbance was measured at 549 and $532 \mathrm{~nm}$. The difference in the absorbance was taken as a measure of the sialic acid content.

Serum GGT levels were estimated by measuring the release of $p$-nitroaniline from gamma glutamyl $p$-nitroanilide in the presence of an acceptor (glycylglycine) $[9,10]$. The GGT content was determined from the graph using $p$-nitroaniline as the standard.

Histopathological studies. Lung tissues were fixed in $10 \%$ formalin, dehydrat- 
ed, and embedded in paraffin wax. Sections $(4 \mu \mathrm{m})$ were stained with eosin and hematoxylin.

Statistical analysis. Experiments were done twice, using 8 animals/subgroup each time; and results were expressed as the mean \pm standard deviation. Statistical evaluation was done by Student's $t$-test.

\section{RESULTS}

\section{Effects of sulphur-containing compounds on lung tumor nodule formation}

There was a significant reduction in tumor nodule formation when the animals were treated with sulphur-containing compounds either simultaneously or after tumor development (Table 1). Untreated control animals developed massive number of tumor nodules on their lungs and were assigned an arbitrary number of 250 [11]. Among the different modalities of drug administration, simultaneous administration of the drugs produced maximum inhibition of tumor formation followed by drug administration after tumor development. Prophylactic administration of the compound did not produce any inhibition in nodule formation. DADS inhibited $90.3 \%$ of tumor nodule formation when the drug was administered simultaneously; but when it was administered after tumor development, it inhibited only $48.5 \%$ of the nodule formation. DAS and AMS produced 55.1 and $54.8 \%$ inhibition when the compounds were administered simultaneously and 49.4 and $45.4 \%$ when drug was administered after tumor development. None of the compounds had any effect when they were administered prophylactically.

\section{Effect of sulphur-containing compounds on the survival rate of tumor-bearing animals}

The effect of sulphur-containing compounds on the survival rate of tumorbearing mice is shown in Table 2 . There was a significant increase in the life span of animals treated with DADS (158.5\%) simultaneously. The percent increase in life span of animals treated with DAS and AMS was 52.1 and $61.0 \%$ respectively.

Table 1. Effect of sulphur-containing compounds on lung tumor colony formation.

\begin{tabular}{lcccccccc}
\hline \multirow{2}{*}{ Drug } & \multicolumn{2}{c}{ Simultaneous } & & \multicolumn{2}{c}{ Developed } & & \multicolumn{2}{c}{ Prophylactic } \\
\cline { 2 - 3 } & $\begin{array}{c}\text { No. of } \\
\text { colonies }\end{array}$ & $\begin{array}{c}\% \\
\text { inhibition }\end{array}$ & & $\begin{array}{c}\text { No. of } \\
\text { colonies }\end{array}$ & $\begin{array}{c}\% \\
\text { inhibition }\end{array}$ & & $\begin{array}{c}\text { No. of } \\
\text { colonies }\end{array}$ & $\begin{array}{c}\% \\
\text { inhibition }\end{array}$ \\
\hline Control & 250 & - & & 250 & - & & 250 & - \\
DAS & $112.2 \pm 14.6^{*}$ & $55.1 \pm 5.9^{*}$ & & $126.5 \pm 17.5^{*}$ & $49.4 \pm 17.6^{*}$ & & 250 & Nil \\
DADS & $24.2 \pm 2.7^{*}$ & $90.3 \pm 1.1^{*}$ & & $128.7 \pm 23.1^{*}$ & $48.5 \pm 9.2^{*}$ & & 250 & Nil \\
AMS & $113.2 \pm 12.9^{*}$ & $54.8 \pm 5.2^{*}$ & & $136.6 \pm 32.2^{*}$ & $45.4 \pm 12.9^{*}$ & & 250 & Nil \\
\hline
\end{tabular}

B16F-10 melanoma cells $\left(1 \times 10^{6}\right)$ were injected into each animal via a lateral tail vein. Different drugs were administered intraperitoneally for 10 consecutive days by various modalities. Controls were treated with vehicle-paraffin oil. Animals were sacrificed on $21 \mathrm{st}$ day, lungs excised, and lung tumor nodules counted. Values are the mean \pm SD. Statistical significance is as follows. Significantly different from untreated control: ${ }^{*} p<0.001$. 
When DADS, DAS, and AMS were administered after tumor development, the increase in life span was $63.8,30.7$, and $29.7 \%$ respectively. None of the three compounds had any effect on the survival rate when administered prior to tumor inoculation.

Effect of sulphur-containing compounds on lung collagen hydroxyproline content

The effect of the sulphur-containing compounds on the lung collagen hydroxyproline content is shown in Table 3. Control tumor-bearing animals showed an increased level of lung collagen hydroxyproline $(19.9 \mu \mathrm{g} / \mathrm{mg}$ protein), which was significantly reduced in the animals treated with sulphur-containing compounds, indicating a decreased tumor burden. The effect was maximum when the compounds were administered simultaneously with tumor cells. Among the tested compounds DADS $(4.6 \mu \mathrm{g} / \mathrm{mg}$ protein) resulted in the lowest level of hydroxyproline content followed by DAS $(7.6 \mu \mathrm{g} / \mathrm{mg}$ protein) and AMS $(8.6 \mu \mathrm{g} / \mathrm{mg}$ protein). In animals treated with DAS, DADS, and AMS after tumor development, the hydroxyproline levels were $6.6,7.4$, and $10.3 \mu \mathrm{g} / \mathrm{mg}$ protein, respectively. Administration of the test compounds prophylactically did not have any effect on the lung collagen hydroxyproline level.

Table 2. Effect of sulphur-containing compounds on the survival rate of metastatic tumorbearing animals.

\begin{tabular}{lccc}
\hline \multirow{2}{*}{ Treatment } & \multicolumn{3}{c}{ Percentage increase in life span $(T-C) / C \times 100$} \\
\cline { 2 - 4 } & \multicolumn{3}{c}{ Treatment modality } \\
\cline { 2 - 4 } & Simultaneous & Developed & Prophylactic \\
\hline Control & 0 & 0 & 0 \\
DAS & $52.1^{*}$ & 30.7 & 0 \\
DADS & $158.5^{*}$ & $63.8^{*}$ & 0 \\
AMS & $61.0^{*}$ & 29.7 & 0 \\
\hline
\end{tabular}

Experimental design is as given in Table 1. Death due to tumor burden was recorded, and the life span was observed. Mean $\pm \mathrm{SD}$. Statistical significance compared to untreated control: ${ }^{*} p<0.001$.

Table 3. Effect of sulphur-containing compounds on the lung collagen hydroxyproline level of tumor-bearing animals.

\begin{tabular}{lccc}
\hline \multirow{2}{*}{ Treatment } & \multicolumn{3}{c}{ Lung collagen hydroxyproline $(\mu \mathrm{g} / \mathrm{mg}$ protein $)$} \\
\cline { 2 - 4 } & \multicolumn{3}{c}{ Treatment modality } \\
\cline { 2 - 4 } & Simultaneous & Developed & Prophylactic \\
\hline Normal & $1.9 \pm 0.1$ & & \\
Control & $19.9 \pm 1.5$ & $6.7 \pm 1.2^{*}$ & $25.2 \pm 1.4$ \\
DAS & $7.6 \pm 0.6^{*}$ & $7.4 \pm 0.7^{*}$ & $23.4 \pm 1.2$ \\
DADS & $4.6 \pm 0.1^{*}$ & $10.3 \pm 1.6^{* *}$ & $30.6 \pm 0.6$ \\
AMS & $8.6 \pm 0.3^{*}$ & \\
\hline
\end{tabular}

Experimental design is as given in Table 1 . Mean \pm SD. Statistically significant from untreated control: ${ }^{*} p<0.001,{ }^{* *} p<0.005$. 


\section{Effect of sulphur-containing compounds on the serum sialic acid levels}

Table 4 documents the effect of sulphur-containing compounds on the serum sialic acid level of the metastatic tumor-bearing animals. The elevated level of serum sialic acid in the control group $(126.8 \mu \mathrm{g} / \mathrm{ml}$ serum) was significantly reduced to $22.8 \mu \mathrm{g} / \mathrm{ml}$ serum by simultaneous administration of DADS. Administration of AMS and DAS reduced the level to 47.6 , and $48.4 \mu \mathrm{g} / \mathrm{ml}$ serum, respectively. DAS $(62.0 \mu \mathrm{g} / \mathrm{ml}$ serum), DADS $(59.4 \mu \mathrm{g} / \mathrm{ml}$ serum $)$, and AMS $(71.0$ $\mu \mathrm{g} / \mathrm{ml}$ serum) produced a significant reduction in the serum sialic acid content when administered after tumor development. None of the compounds showed any effect in reducing the elevated level of serum sialic acid when administered prophylactically.

\section{Effect of the sulphur-containing compounds on serum GGT levels}

Serum GGT levels resulting from the various treatment modalities of the compounds are shown in Table 5. GGT levels were higher in the control animals (102.7 nmol $p$-nitroaniline/ml serum), which was significantly reduced to 16.5 nmol $p$-nitroaniline $/ \mathrm{ml}$ serum when the animals were simultaneously treated with

Table 4. Effect of sulphur-containing compounds on the serum sialic acid level of metastatic tumor-bearing animals.

\begin{tabular}{lccc}
\hline \multirow{2}{*}{ Treatment } & \multicolumn{3}{c}{ Serum sialic acid $(\mu \mathrm{g} / \mathrm{ml}$ serum $)$} \\
\cline { 2 - 4 } & Simultaneous & Dreatment modality \\
\cline { 2 - 4 } & $21.3 \pm 0.5$ & & Prophylactic \\
\hline Normal & $126.8 \pm 10.3$ & & \\
Control & $48.4 \pm 3.4^{*}$ & $62.0 \pm 7.6^{* *}$ & $168.0 \pm 16.0$ \\
DAS & $22.8 \pm 1.6^{*}$ & $59.4 \pm 8.3^{* *}$ & $94.0 \pm 7.5$ \\
DADS & $47.6 \pm 1.5^{*}$ & $71.0 \pm 12.0^{* *}$ & $174.0 \pm 13.4$ \\
AMS & & & \\
\hline
\end{tabular}

Experimental design is as given in Table 1. Animals were sacrificed on the 21 st day, blood collected by heart puncture, and serum separated. Values are the mean \pm SD. Statistically significant from untreated control: ${ }^{*} p<0.001,{ }^{* *} p<0.005$.

Table 5. Effect of sulphur-containing compounds on the serum GGT level of metastatic tumor-bearing animals.

\begin{tabular}{lccc}
\hline & \multicolumn{3}{c}{ GGT (nmol $p$-nitroaniline/ml serum) } \\
\cline { 2 - 4 } Treatment & \multicolumn{3}{c}{ Treatment modality } \\
\cline { 2 - 4 } & Simultaneous & Developed & Prophylactic \\
\hline Normal & 21 & & \\
Control & $102.7 \pm 1.9$ & $68.0 \pm 2.0^{*}$ & $73.0 \pm 2.2$ \\
DAS & $59.5 \pm 11.8^{*}$ & $60.0 \pm 6.0^{*}$ & $88.0 \pm 11.4$ \\
DADS & $16.5 \pm 0.9^{*}$ & $50.0 \pm 10.0^{*}$ & $76.0 \pm 5.8$ \\
AMS & $60.0 \pm 1.6^{*}$ & \multicolumn{3}{c}{} \\
\hline
\end{tabular}

Experimental design is as given in Table 1. Animals were sacrificed on the 21 st day, blood collected by heart puncture, and serum separated. Values are the mean $\pm S D$. Statistically significant from untreated control: ${ }^{*} p<0.001$. 
(a)

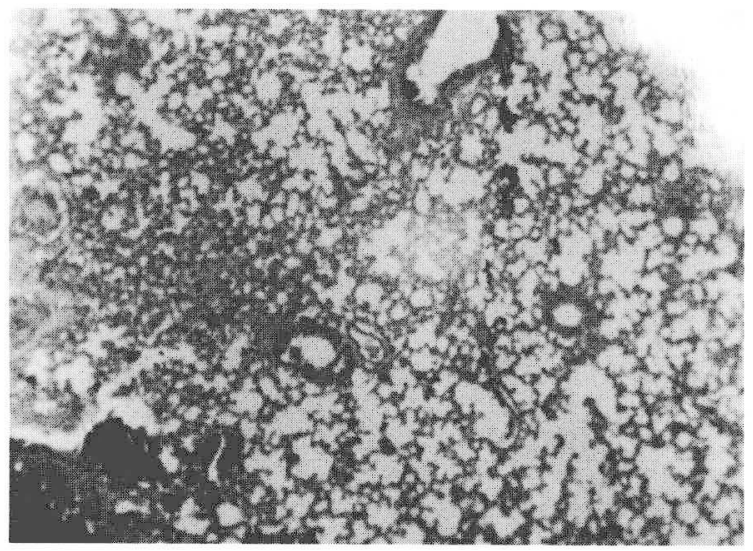

(b)

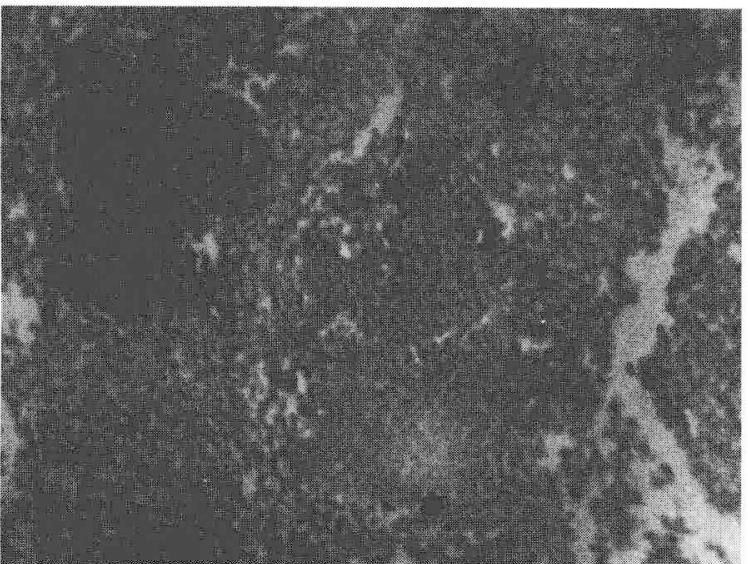

(c)

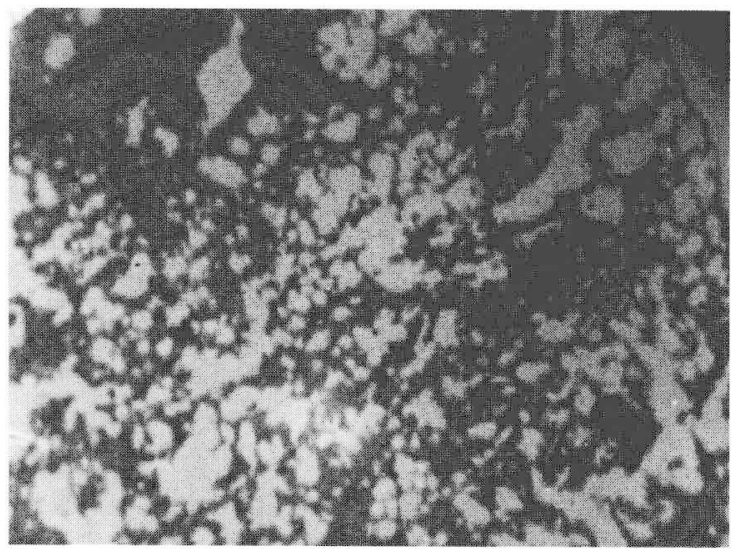

Fig. 1. Histopathological analysis of lungs from metastatic tumor-bearing mice. (a) Normal. (b) Control (paraffin-treated). (c) Treated with DADS by simultaneous treatment modality.

Vol. 27, No. 3, 1999 
DADS. Administration of AMS and DAS reduced the GGT levels to 60.0 and 59.5 nmol $p$-nitroaniline/ml serum, respectively. Administration of drugs after tumor development also led to reduced GGT levels, which, in the case of AMS, was 50.0 nmol $p$-nitroaniline/ml serum. The level for DADS was $60.0 \mathrm{nmol} p$-nitroaniline/ $\mathrm{ml}$ serum; and that for DAS, $68.0 \mathrm{nmol} p$-nitroaniline $/ \mathrm{ml}$ serum. None of the compounds caused any reduction in the GGT level when administered prophylactically.

\section{Effect of sulphur-containing compounds as judged histopathologically}

Lungs in the control animals showed infiltration of the neoplastic cells around the main bronchioles extending to the pleura (Fig. 1b). A clear area of necrosis around the alveolar passage and bronchioles was seen. Metastatic tumorbearing animals treated with sulphur-containing compounds showed a significant reduction in their tumor mass. Alveoli and pleura were relatively tumor cell free. This reduction was found to be extensive in the case of simultaneous treatment with DADS (Fig. 1c). There was no significant change in the lung pathology when the sulphur-containing compounds were administered prophylactically.

\section{DISCUSSION}

In the present study we analyzed the effects of DAS, DADS, and AMS on the inhibition of lung metastasis induced by B16F-10 melanoma cells. Animals treated with sulphur compounds given along with the tumor cells showed considerable inhibition of tumor metastasis. DADS administered simultaneously along with the tumor cells showed the maximum effect ( $90.3 \%$ reduction). This was correlated with an increase in the life span of the metastatic tumor-bearing animals.

Inhibition of lung metastasis was not uniform among the three modalities of drug administration. Inhibition was profound when the compounds were administered simultaneously. Drug administration after tumor development also showed considerable inhibition of metastasis, whereas prophylactic administration had no effect. The overall antimetastatic effect observed was more significant in the case of DADS compared to DAS and AMS.

During lung fibrosis collagen is deposited on the lungs. Hence, we determined lung collagen hydroxyproline levels as a marker for lung fibrosis. Lung collagen hydroxyproline levels, which were drastically increased in the tumor-bearing control lungs was significantly reduced by DADS, DAS, and AMS when the drugs were given simultaneously with the tumor cells or after tumor development.

Secretion of glycoproteins [12] and shedding of gangliosides have been reported during metastasis. Sialic acid, an acylated derivative of neuraminic acid, usually occurs as a terminal component of carbohydrate chains of glycoproteins and glycolipids. Estimation of sialic acid present on the surface of malignant cells has been correlated directly with the ability of the cells to metastasize $[8,13]$. We observed that the increased sialic acid level in the metastatic tumor-bearing 
animals was significantly reduced in the animals treated with the sulphur compounds simultaneously and after tumor development. GGT, a marker of cellular proliferation, was increased in the serum of the tumor-bearing animals compared with its level in normal animals. The increased serum GGT was reduced by treatment with the sulphur compounds.

The mechanism of inhibition of metastasis by sulphur compounds is not known at present. We assumed that the observed inhibition of metastasis by these sulphur compounds may be due to the initial cleavage of the disulphide bonds and further binding to the active site of metalloproteases, thereby inactivating these enzymes [14]. However, the nature and kinetics of the binding is not known at present.

\section{REFERENCES}

1. Fidler, I.J., and Hart, I.R. (1982): Biological diversity in metastatic neoplasm: Origins and implications. Science, 217, 998-1001.

2. Schirmaker, V. (1985): Experimental approaches, theoretical concepts and impacts for treatment strategies. Adv. Cancer Res., 43, 1-32.

3. Liotta, L.A., Rao, C.N., and Barsky, S.H. (1993): Tumor invasion and extra-cellular matrix. Lab. Invest., 49, 636.

4. Menon, L.G., Kuttan R., and Kuttan, G. (1995): Inhibition of lung metastasis in mice induced by B16F-10 melanoma cells by polyphenolic compounds. Cancer Lett., 95, 221-225.

5. Menon, L.G., Kuttan, R., Nair, M.G., Chang, Y.C., and Kuttan, G. (1998): Effect of isoflavones genistein and daidzein in the inhibition of lung metastasis induced by B16F-10 melanoma cells. Nutr. Cancer, 30, 14-17.

6. Albini, A., Agostini, F.D., Giunciuglio, D., Paglieri, I., Balansky, R., and Flora, S.D. (1995): Inhibition of invasion, gelatinase activity, tumour take and metastasis of malignant cells by $N$-acetylcysteine. Int. J. Cancer, 61, 121-129.

7. Bergman, I., and Loxley, R. (1970): The determination of hydroxyproline in urine hydrolysate. Clin. Chim. Acta, 27, 347-349.

8. Bhavanandan, V.P., Kallic, A.W., Banks, J., Kemper, J.G., and Davidson, E.A. (1981): Partial characterisation of sialoglycopeptides produced by cultured human melanoma cells and melanocytes. Biochemistry, 20, 3586-3594.

9. Tate, S.S., and Meister, A. (1974): Inhibition of gamma glutamyl transpeptidase with aminoacids, peptides and derivatives and analogs of glutathione. J. Biochem., 23, 15931602.

10. Bizik, J., Grofova, M., and Svec, J. (1985): Release of a Mr. 14,000 glycoprotein in culture media of certain human sarcoma and melanoma cell lines. Eur. J. Cancer Clin. Oncol., 21, 311-324.

11. Liotta, L.A. (1986): B16F-10 cells readily cause pulmonary metastasis after injection through tail vein. Cancer Res., 46, 1-4.

12. Hersey, P. (1985): Review of melanoma antigens recognised by monoclonal antibodies: Their functional significance and applications in diagnosis and treatment of melanoma. Pathology, 11, 346-354.

13. Vedolva, E., and Borovansky, J. (1994): Evaluation of serum sialic acid fractions as marker for malignant melanoma. Cancer Lett., 78, 171-175.

14. Springman, E., Angleton, E., Birkedal-Hansen, H., and Van Wart, H.E. (1990): Multiple modes of activation of latent human fibroblast collagenase: Evidence for the role of Cys 73 active-site zinc complex in latency and a "cysteine switch" mechanism for activation. Proc. Natl. Acad. Sci. U.S.A., 87, 364-368. 